\title{
Mechanical properties of wood-derived silicon carbide aluminum-alloy composites as a function of temperature
}

\author{
T.E. Wilkes \\ Department of Materials Science and Engineering, Robert R. McCormick School of Engineering \\ and Applied Science, Northwestern University, Evanston, Illinois 60208-3108 \\ J.Y. Pastor \\ Departamento de Ciencia de Materiales, Universidad Politécnica de Madrid, E. T. S. de Ingenieros \\ de Caminos, 28040 Madrid, Spain \\ J. Llorca \\ Departamento de Ciencia de Materiales, Universidad Politécnica de Madrid, E. T. S. de Ingenieros \\ de Caminos, 28040 Madrid, Spain; and Instituto Madrileño de Estudios Avanzados en Materiales \\ (IMDEA-Materiales) E. T. S. de Ingenieros de Caminos, 28040 Madrid, Spain \\ K.T. Faber ${ }^{\text {a) }}$ \\ Department of Materials Science and Engineering, Robert R. McCormick School of Engineering \\ and Applied Science, Northwestern University, Evanston, Illinois 60208-3108
}

(Received 16 January 2008; accepted 3 March 2008)

\begin{abstract}
The mechanical behavior [i.e., stiffness, strength, and toughness $\left(\mathrm{K}_{\mathrm{IC}}\right)$ ] of $\mathrm{SiC}$ $\mathrm{Al}-\mathrm{Si}-\mathrm{Mg}$ metal-ceramic composites (50:50 by volume) was studied at temperatures ranging from 25 to $500{ }^{\circ} \mathrm{C}$. The $\mathrm{SiC}$ phase was derived from wood precursors, which resulted in an interconnected anisotropic ceramic that constrained the pressure melt-infiltrated aluminum alloy. The composites were made using SiC derived from two woods (sapele and beech) and were studied in three orthogonal orientations. The mechanical properties and corresponding deformation micromechanisms were different in the longitudinal (LO) and transverse directions, but the influence of the precursor wood was small. The LO behavior was controlled by the rigid SiC preform and the load transfer from the metal to the ceramic. Moduli in this orientation were lower than the Halpin-Tsai predictions due to the nonlinear and nonparallel nature of the Al-filled pores. The $\mathrm{LO} \mathrm{K}_{\mathrm{IC}}$ agreed with the Ashby model for the $\mathrm{K}_{\mathrm{IC}}$ contribution of ductile inclusions in a brittle ceramic.
\end{abstract}

\section{INTRODUCTION}

Porous wood-derived silicon carbide $(\mathrm{SiC})$ has been extensively studied and has been considered for use in light-weight structural materials, catalyst supports, heat exchangers, high-temperature molten-metal filters, and composite reinforcements. ${ }^{1-6}$ Previous research ${ }^{7-9}$ has shown the viability of infiltrating molten metal into the pore space of wood-derived $\mathrm{SiC}$, but characterization of the resulting metal-ceramic composites (MCCs) was limited to room-temperature properties such as compressive strength, modulus, and flexural strength $\left(\sigma_{\mathrm{f}}\right)$. The current work aimed to expand on these findings by studying the strength and fracture toughness $\left(\mathrm{K}_{\mathrm{IC}}\right)$ of MCCs made from various wood precursors as a function of

\footnotetext{
a) Address all correspondence to this author.

e-mail: k-faber@northwestern.edu

DOI: $10.1557 / J M R .2008 .0197$
}

temperature, and to provide a better understanding of the deformation and failure micromechanisms that control their mechanical behavior.

Wood is a honeycomb-like anisotropic material with pores aligned both parallel and perpendicular to the long axis of the tree, which is commonly referred to as the "axial direction." 10,11 Both the diameter of the pores and the spatial distribution of the pores can vary between wood species. Hardwoods have a bimodal distribution of axially oriented pores, and the larger and smaller diameter pores are referred to as "vessels" and "fiber cells," respectively. The pores running perpendicular to the axial direction, "rays," are radially oriented and originate at the center of the tree. The third orthogonal direction in wood, the tangential direction, is tangent to the growth rings (i.e., the concentric circles that are often visible to the naked eye). These rings are a result of changing growth rates that affect the diameter of the vessels. Throughout the processing of wood-derived $\mathrm{SiC}$, 
the wood microstructure is retained, resulting in a honeycomb-like SiC material. The porosity, spatial distribution, and orientation of the pores affect the properties of the porous $\mathrm{SiC},{ }^{12,13}$ but the influence of these factors, which are determined by the wood precursor, on the mechanical properties of the MCCs are not known.

Producing $\mathrm{SiC}$ from wood offers several advantages over conventional ceramic processing methods. ${ }^{1}$ Low processing temperatures use less energy than sintering processes, the multitude of different wood species allows for tailored microstructures, and near-net-shape parts can be produced with little or no machining of the ceramic. These advantages make the processing of composites using melt-infiltration techniques easier due to elimination of the need for binders, sintering, or other complexities involved in making cohesive preforms. ${ }^{14}$ By applying sufficiently high temperatures and pressures, dense parts can be produced without concern for metal-ceramic wettability; however, reactions between the molten metal and ceramic may occur and may lead to impurities in the composite. For example, pure aluminum reacts with $\mathrm{SiC}$ to form aluminum carbide $\left(\mathrm{Al}_{4} \mathrm{C}_{3}\right)$, a brittle intermetallic compound that can diminish mechanical properties. ${ }^{15} \mathrm{Al}-$ loying additions of silicon and magnesium deter this reaction, and improve wetting between $\mathrm{Al}$ and $\mathrm{SiC}$; the particular aluminum alloy used in this work, containing $13 \mathrm{wt} \% \mathrm{Si}$ and $9 \mathrm{wt} \% \mathrm{Mg}$, was shown to optimize these effects in $\mathrm{SiC}-\mathrm{Al}$ composites. ${ }^{16}$

Addition of a metal to a brittle ceramic can increase the $\mathrm{K}_{\mathrm{IC}}$ and ductile response of the material while retaining most of the stiffness and strength imparted by the ceramic. ${ }^{17,18}$ By using a porous preform, the metal acts as a system of ductile inclusions within the interconnected ceramic. Increased $\mathrm{K}_{\mathrm{IC}}$ results from mechanisms such as plastic stretching of the inclusions, decohesion between the metal and the ceramic, and fracture of the ceramic phase near the inclusions, all of which increase the work required for crack propagation. ${ }^{19,20}$ Also, residual stresses can increase the initial force needed for crack propagation and induce plastic strain in inclusions, which can act to shield a crack tip. ${ }^{18}$

The objective of this work is to study the mechanical properties and the underlying deformation and fracture micromechanisms of the wood-derived $\mathrm{SiC}-\mathrm{Al}$ alloy MCCs from 25 to $500{ }^{\circ} \mathrm{C}$. The composite properties are compared to those of the $\mathrm{Al}-\mathrm{Si}-\mathrm{Mg}$ alloy and, where data are available, to the porous wood-derived SiC. Predictions for the elastic modulus and the longitudinal $\mathrm{K}_{\mathrm{IC}}$ are obtained from constituent properties and the appropriate models: Halpin-Tsai bounds ${ }^{21}$ for the elastic properties; and the model of the effect of ductile particle reinforcement on the $\mathrm{K}_{\mathrm{IC}}$ of brittle materials by Ashby et al. ${ }^{19}$ Comparisons of the model predictions with the experimental results provide information on the main microstructural factors that control the mechanical behavior of the novel composites as a function of temperature and orientation.

\section{EXPERIMENTAL DETAILS}

\section{A. Sample processing}

For this study, two hardwoods were used as starting materials: beech (BE) (Fagus sylvatica); and sapele (SA) (Entandrophragma cylindricum). The process of manufacturing the MCCs involved, first, pyrolyzing the wood in an argon atmosphere at $1000{ }^{\circ} \mathrm{C}$ for $1 \mathrm{~h}$. Next, the resulting amorphous carbon was heated in a vacuum to $1550{ }^{\circ} \mathrm{C}$ for another hour with a stoichiometric excess of silicon powder $(99.6 \mathrm{wt} \% \mathrm{Si})$. Once molten, the silicon reacted with the carbon to form $\beta$-SiC. This reaction promoted wetting, and the silicon was wicked into the cylindrical pores. If necessary, this reaction step was repeated to minimize the amount of residual carbon in the specimens.

Upon solidification, some pores retain excess silicon, which can be removed by using carbon felt or an acid etch. Using carbon felt requires reheating the $\mathrm{Si} / \mathrm{SiC}$ material to above the melting point of $\mathrm{Si}$ in an inert atmosphere. The felt wicks the excess Si out of the pores, but some residual Si may still remain. An acid solution consisting of 50:50 vol\% concentrated hydrofluoric and nitric acids can also be used to remove the excess silicon. The nitric and hydrofluoric acids act to cyclically oxidize the $\mathrm{Si}$ into $\mathrm{SiO}_{2}$ and etch away the $\mathrm{SiO}_{2}$, respectively. In this work, samples were etched for at least 14 days to ensure complete removal of the excess silicon. In the final processing step, the porous $\mathrm{SiC}$ preforms were meltinfiltrated with an $\mathrm{Al}-13 \mathrm{Si}-9 \mathrm{Mg}$ alloy using a gaspressure liquid-metal infiltration furnace. ${ }^{8,22}$ A cast cylinder of the alloy was placed on top of specimens in a graphite crucible. The furnace was heated in a vacuum to $750{ }^{\circ} \mathrm{C}$, whereupon the aluminum alloy melted and formed a seal with the crucible walls, isolating the porous $\mathrm{SiC}$ in a vacuum environment. The furnace was then pressurized using high-purity argon to $3.5 \mathrm{MPa}$, which forced the molten aluminum alloy into the pores.

The densities of the $\mathrm{SiC}$ preforms, $\mathrm{Al}-\mathrm{Si}-\mathrm{Mg}$ alloy, and MCCs were measured using Archimedes' method, as detailed in ASTM-C $373 .{ }^{23}$ An Autopore IV mercury porosimeter (Micromeritics, Norcross, GA) was used to measure the pore-size distribution of the $\mathrm{BE}$ and $\mathrm{SA}$ carbon $(\mathrm{C})$ and $\mathrm{SiC}$.

\section{B. Mechanical characterization}

Following the procedures above, MCC bars measuring $3.0 \mathrm{~mm} \times 3.0 \mathrm{~mm} \times 30 \mathrm{~mm}$ were machined to measure the bending strength and modulus, while single-edge notched bars with dimensions of $3.0 \mathrm{~mm} \times 3.0 \mathrm{~mm} \times$ $12 \mathrm{~mm}$ were used to measure the $\mathrm{K}_{\mathrm{IC}}$. The notches were 
introduced using a slow-speed diamond saw and measured $0.5 \mathrm{~mm}$ deep and $0.2 \mathrm{~mm}$ wide. The notch tips had a square cross section with rounded corners. All bend tests were carried out in a three-point bend configuration, as shown schematically in Fig. 1, which also depicts the three specimen orientations. The Al-filled pores in longitudinal (LO) samples are oriented normal to the fracture surfaces. Transverse samples are oriented with the Al-filled pores lying in the fracture plane and either parallel (TR1) or perpendicular (TR2) to the applied load. Bars of the $\mathrm{Al}-\mathrm{Si}-\mathrm{Mg}$ alloy were also machined and tested using the same dimensions and specifications as those for the MCC specimens. For the purposes of modeling the fracture behavior, the tensile properties of the $\mathrm{Al}-\mathrm{Si}-\mathrm{Mg}$ alloy were also measured. In particular, the yield stress and Young's modulus were determined with cylindrical samples according to ASTM standard E8. ${ }^{24}$ The specimen gauge diameter and gauge length were 6.4 and $28.6 \mathrm{~mm}$, respectively.

Mechanical $\left(\sigma_{\mathrm{f}}\right.$ and $\left.\mathrm{K}_{\mathrm{IC}}\right)$ tests were conducted with an Instron 8501 (Norwood, MA) mechanical testing machine, and a frame-mounted MTS 653 furnace (Eden Prairie, MN) was used to heat specimens for tests performed above room temperature. A linear variable differential transducer was used to measure the displacement. Tests were conducted using a displacement rate of $100 \mu \mathrm{m} / \mathrm{min}$, a heating rate of $10^{\circ} \mathrm{C} / \mathrm{min}$, and a hold time of $20 \mathrm{~min}$. The $\sigma_{\mathrm{f}}$ was calculated according to ASTM $\mathrm{C} 1161,{ }^{25}$ and the $\mathrm{K}_{\mathrm{IC}}$ was calculated according to the sample parameters given in Guinea et al. $^{26}$ and ASTM

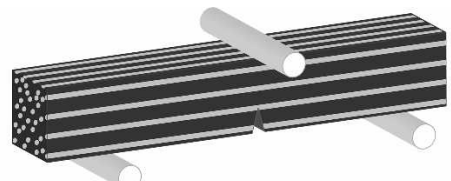

\section{Longitudinal (LO) Orientation}

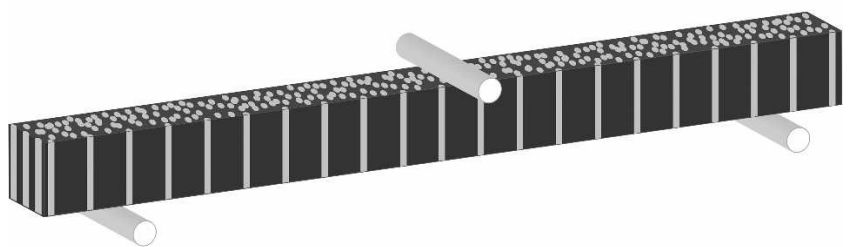

Transverse 1 (TR1) Orientation

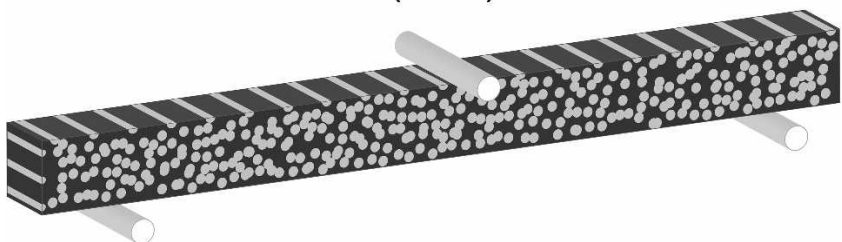

Transverse 2 (TR2) Orientation

FIG. 1. Bend test sample orientations: a notched LO specimen (top) for $\mathrm{K}_{\mathrm{IC}}$ measurements and TR1 (middle) and TR2 (bottom) specimens without notches for flexural modulus or strength measurements.
$\mathrm{C} 1421^{27}$ using between three and six samples for each testing condition. Specimen microstructures, fracture surfaces, and crack paths were examined by scanning electron microscopy (S3400N SEM; Hitachi, Pleasanton, CA).

Tests to measure the evolution of the flexural modulus with temperature were carried out in an Instron 4505 mechanical testing machine with a custom-built furnace (Entech, Ängelholm, Sweden). The mid-span deflection of the bend bar was measured through a quartz window in the furnace using a high-resolution laser extensometer (model 2211; Zygo, Middlefield, CT). The displacement rate, heating rate, and hold time were $100 \mu \mathrm{m} / \mathrm{min}$, $10^{\circ} \mathrm{C} / \mathrm{min}$, and $20 \mathrm{~min}$, respectively. The flexural modulus was calculated from the slope of the force versus mid-span displacement curves. ${ }^{25}$ For each material and orientation, one specimen was used to measure elastic loading-unloading curves for the entire range of testing temperatures. After each measurement, the specimen was heated to the next set point and held for 20 min before repeating the loading-unloading measurement.

Tensile testing of the aluminum alloy was conducted in an MTS 808 mechanical testing machine, with a frame-mounted ATS 3210 (Butler, PA) furnace and an extensometer (model 632-13B-21; MTS). Tests were carried out under displacement control with a displacement rate of $1 \mathrm{~mm} / \mathrm{min}$. Samples tested above room temperature were heated under load control without a programmed heating rate. Before testing, the temperature was held until the extensometer reading stabilized (i.e., when both the specimen and fixture had reached thermal equilibrium). The Young's modulus of the aluminum alloy was measured as the slope of the tensile stress versus strain curve, and the yield strength was calculated using the offset method at a $0.2 \%$ strain.

\section{RESULTS}

\section{A. Microstructure}

Micrographs of both axial and radial sections of BEand SA-derived $\mathrm{C}, \mathrm{SiC}$, and $\mathrm{MCC}$ are shown in Figs. 2(a)-2(d), 2(e)-2(h), and 2(i)-2(l), respectively. The replicated wood characteristics, including the three cell types, are most evident in the carbon cross sections. The axially oriented pores propagate into and out of the page in the axial sections, and vertically in the radial sections. The radially oriented pores are vertical in the axial sections, and run into and out of the page in the radial sections. In Fig. 2(a), the radial pores, indicated by the vertical arrow, intersect a relatively dense horizontal band, indicated by the horizontal arrow that separates the late wood (bottom) from the early wood (top). The features of SA specimens are generally larger than their BE counterparts, but the late-to-early wood transitions are 

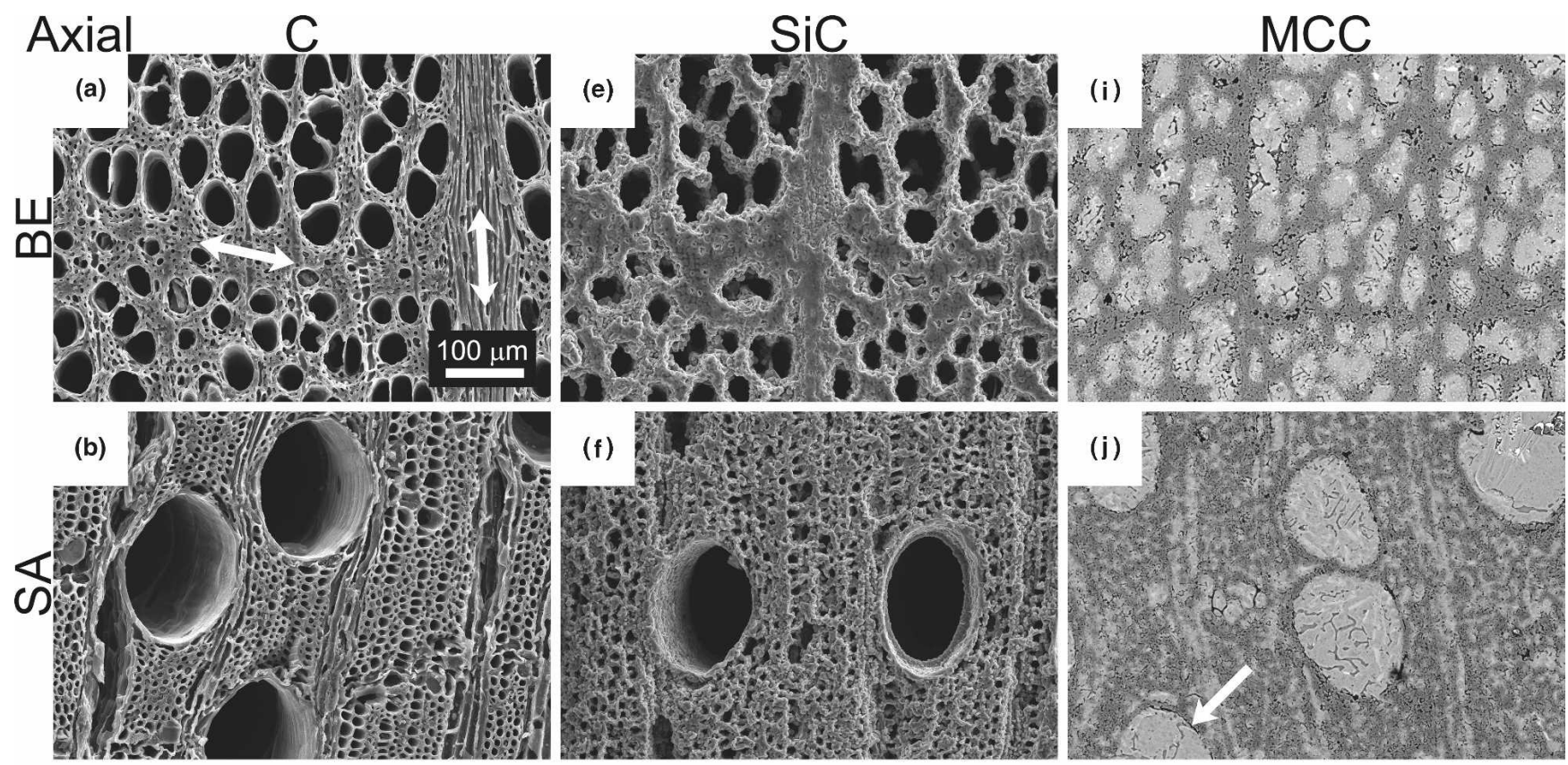

\section{Radial}
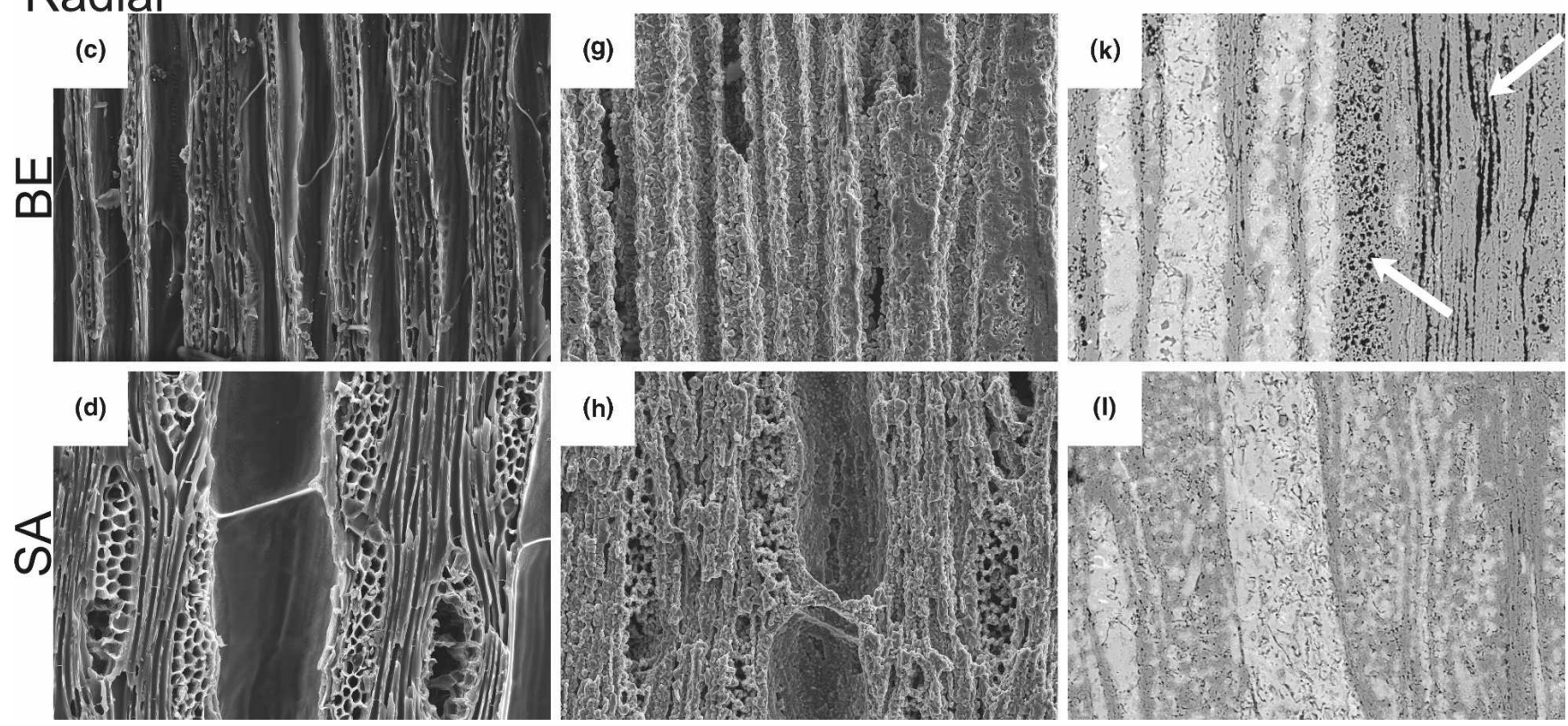

FIG. 2. SEM micrographs of the BE-C, SA-C, and SA-SiC, BE-SiC, and backscattered electron micrographs of the BE-MCC and SA-MCC. Cross sections are perpendicular to either the axial direction (top) or the radial direction (bottom). BE and SA micrographs are on the top and bottom of each half, respectively, and the columns depict, from left to right, the C, SiC, and MCCs. In (a), the vertical arrow indicates the band of radially oriented pores and the late and early wood are separated by the horizontal arrow. In (j), the arrow points to an area of decohesion along the metal-ceramic interface. In (k), the arrows point to closed porosity oriented in both the radial (left) and axial (right) directions.

less distinct (i.e., pore diameters remain relatively constant throughout growth seasons).

Upon conversion to $\mathrm{SiC}$, the reaction between molten silicon and amorphous carbon to form $\mathrm{SiC}$ was accompanied by a volume change of about $50 \%{ }^{28}$ While the overall specimen dimensions did not significantly change, the volume change was accommodated within the pores. This resulted in decreased pore diameters, but some of the pore walls in the BE specimens were damaged, which led to some effectively larger pores [Fig. 2(e)]. Most of the smaller diameter pores were no longer present in the BE-SiC [Figs. 2(e) and 2(g)] but were observed in the SA-SiC [Figs. 2(f) and 2(h)]. Measurements of the pore-size distributions, shown in Fig. 3, confirmed these observations, with the peaks representing porosity smaller than $1 \mu \mathrm{m}$ in the $C$ curves almost completely disappearing once the material was converted to $\mathrm{SiC}$. 

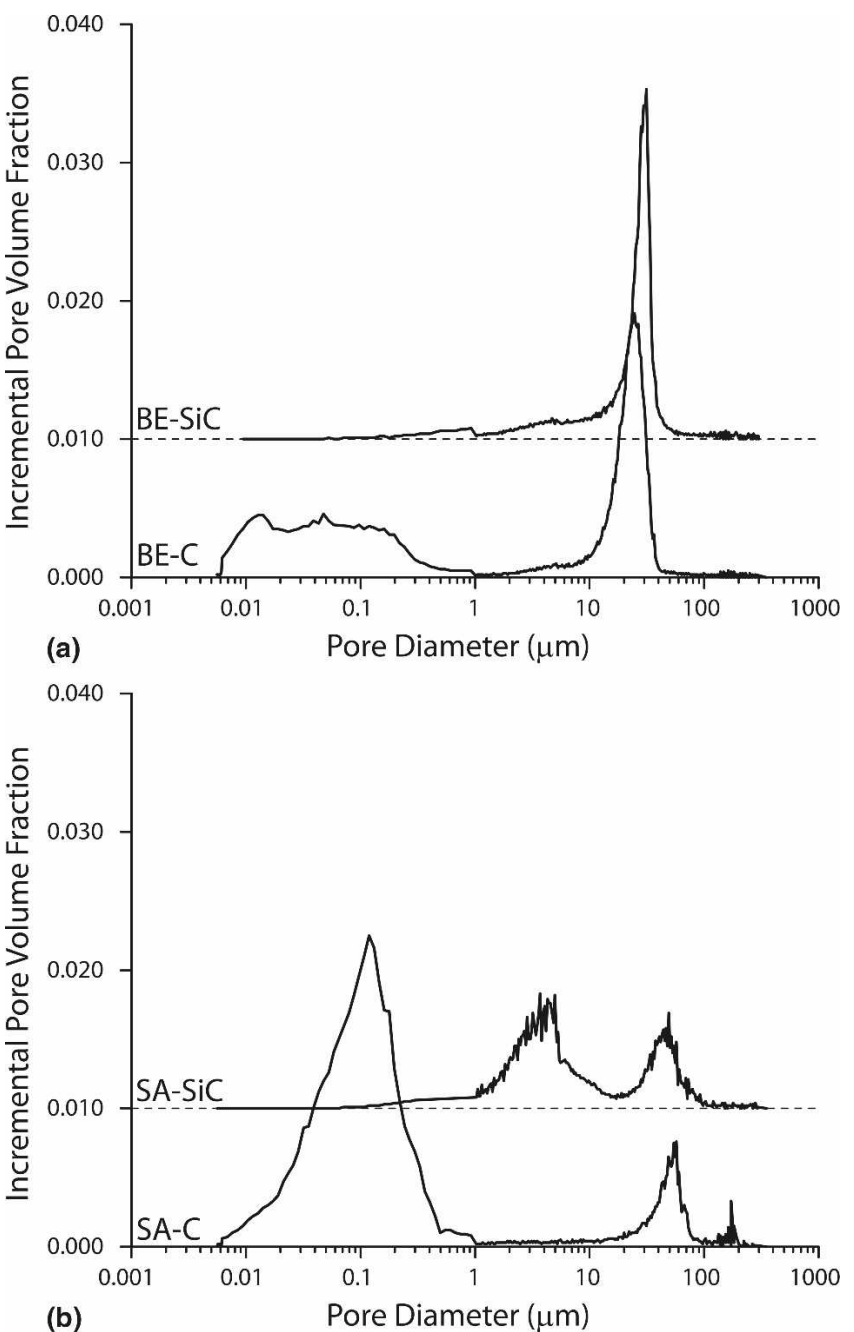

FIG. 3. Incremental porosity volume fraction versus pore diameter, measured by mercury intrusion porosimetry, of the (a) BE-C and $\mathrm{BE}-\mathrm{SiC}$ and the (b) SA-C and SA-SiC. The SiC curves are offset vertically by 0.01 .

A 1-h hold at $1550{ }^{\circ} \mathrm{C}$ was insufficient to completely convert the entire $\mathrm{C}$ scaffold to $\mathrm{SiC}$ for the sample sizes used in this study. As carbon in the smaller pores reacted, pores closed due to volume expansion, impeding further $\mathrm{C}$ to $\mathrm{SiC}$ conversion. Most of the residual $\mathrm{C}$ was converted to $\mathrm{SiC}$ after repeating this reaction step. Small amounts of residual carbon were observed in both specimen types. Based on the theoretical SiC density of $3.21 \mathrm{~g} / \mathrm{cm}^{3}$, specific gravity measurements of the BE-SiC and $\mathrm{SA}-\mathrm{SiC}$, shown in Table I, indicated the presence of $4 \mathrm{vol} \%$ residual carbon. This is an upper bound as the calculation did not take into account any closed porosity in the specimens, which can result from the volume expansion and is visible in the BE-MCC shown in Fig. 2(k). The areas indicated by the arrows correspond to smalldiameter pores that were pinched closed due to the volume expansion that occurs during the $\mathrm{C} \rightarrow \mathrm{SiC}$ reaction.

All four MCC images [Figs. 2(i)-2(1)] were captured
TABLE I. Apparent porosity and specific gravity of BE- and SAderived $\mathrm{SiC}$ and MCCs.

\begin{tabular}{lcc}
\hline \hline Materials & Apparent porosity $(\%)$ & Apparent specific gravity $\left(\mathrm{g} / \mathrm{cm}^{3}\right)$ \\
\hline BE-SiC & $50 \pm 3$ & $3.14 \pm 0.02$ \\
SA-SiC & $51 \pm 3$ & $3.18 \pm 0.03$ \\
BE-MCC & $4 \pm 2$ & $2.84 \pm 0.02$ \\
SA-MCC & $5 \pm 3$ & $2.82 \pm 0.07$ \\
Al-Si-Mg & $5 \pm 3$ & $2.49 \pm 0.04$ \\
\hline \hline
\end{tabular}

in backscattered electron mode, and the infiltrated aluminum appeared lighter than the SiC. The porosity and specific gravity of both the MCC and bulk metal, which contained shrinkage porosity, are reported in Table I. Higher magnification scanning electron micrographs of the composites showed the $\mathrm{Al}-\mathrm{Si}-\mathrm{Mg}$ alloy precipitate structure in both the bulk specimens [Fig. 4(a)] and in the composites [Fig. 4(b)]. The microstructure was made up of a continuous $\mathrm{Al}$ phase (light gray) that included both elongated crystals of primary Si (dark gray) and irregularly shaped $\mathrm{Mg}_{2} \mathrm{Si}$ precipitates (black), which were identified using energy dispersive $\mathrm{x}$-ray spectroscopy. The overall microstructure was similar in both materials and was typical of hypereutectic $\mathrm{Al}-\mathrm{Si}-\mathrm{Mg}$ alloys that were slowly cooled from processing temperatures. ${ }^{29}$ The $\mathrm{Si}$ crystals in the bulk alloy were larger than those in the composites because the pore size limited growth in the latter. Also, $\mathrm{SiC}$ is known to catalyze the nucleation of $\mathrm{Si}$ crystals in composites with hypereutectic $\mathrm{Al}-\mathrm{Si}$ alloys. This results in grain refinement and a larger number of primary Si crystals per unit volume. ${ }^{30}$

\section{B. Flexural test data}

\section{Flexural modulus}

The flexural moduli of the MCCs and Al alloy are shown as a function of temperature for each orientation in Fig. 5. The dashed lines represent Halpin-Tsai predictions, ${ }^{21}$ which were calculated according to

$$
\frac{E^{*}}{E_{\mathrm{Al}}}=\frac{1+\xi \eta V_{\mathrm{SiC}}}{1-\eta V_{\mathrm{SiC}}},
$$

and

$$
\eta=\frac{E_{\mathrm{SiC}} / E_{\mathrm{Al}}-1}{E_{\mathrm{SiC}} / E_{\mathrm{Al}}+\xi},
$$

where $E^{*}$ is the composite modulus and $E_{\mathrm{Al}}$ is the modulus of the aluminum alloy, which was taken as the experimentally measured flexural modulus of the bulk metal. The modulus of the $\mathrm{SiC}, \mathrm{E}_{\mathrm{SiC}}$, was assumed to be constant in the temperature range of this study, and was taken to be $408 \mathrm{GPa}$, which has been previously measured by nanoindentation of the wood-derived $\mathrm{SiC} .{ }^{31}$ For simplicity, the $\mathrm{SiC}$ volume fraction, $\mathrm{V}_{\mathrm{SiC}}$, was taken as 

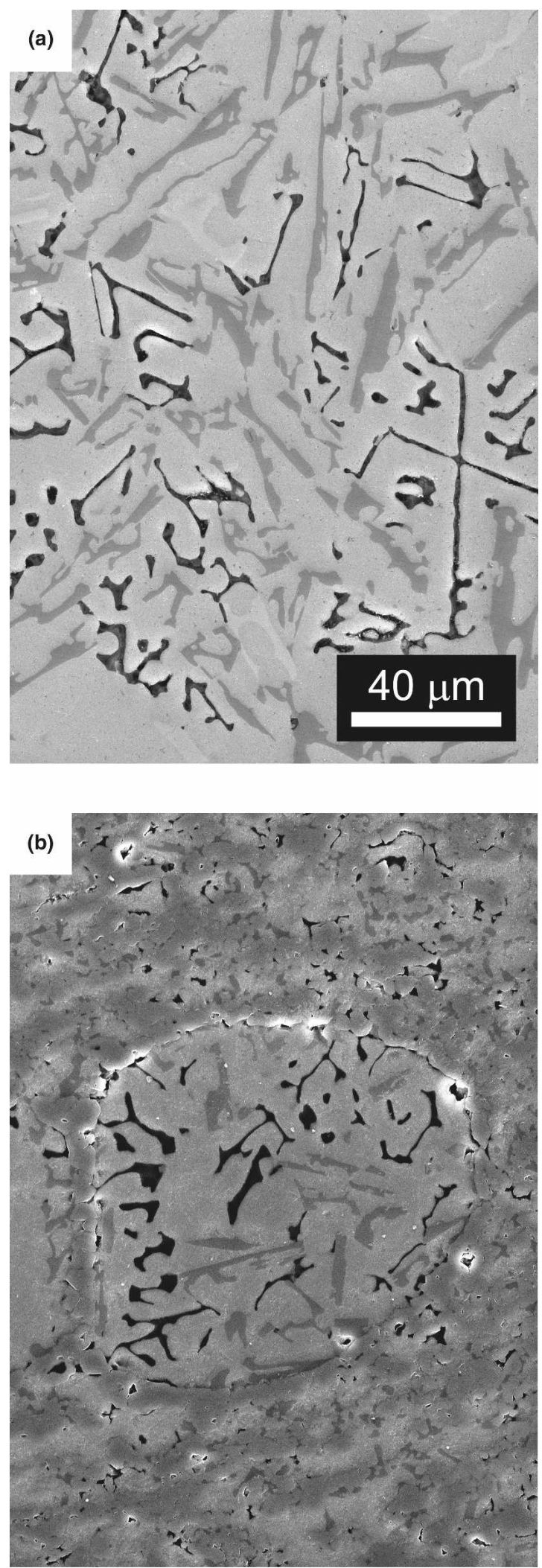

FIG. 4. SEM micrographs of the $\mathrm{Al}-\mathrm{Si}-\mathrm{Mg}$ microstructure in the (a) bulk metal specimens and the (b) Al-Si-Mg filled pore of a SA-MCC. Large primary Si crystals (dark gray) and $\mathrm{Mg}_{2} \mathrm{Si}$ precipitates (black) were observed within the Al matrix (light gray) in both cases.
0.50 for both the BE-MCCs and SA-MCCs. For a fiberreinforced metal-matrix composite, the empirical factor, $\xi$, is a function of both the reinforcement geometry and distribution, and also of the composite loading conditions. For this work, the $\xi$ values used were those reported for uniaxial composites: infinity for the LO orientation; and 0.50 for the TR1 and TR2 orientations. ${ }^{21}$ It should be noted that, in the case of $\xi \rightarrow \infty$, Eq. (1) reduces to the Voigt isostrain model; in the case of $\xi \rightarrow$ 0, Eq. (1) reduces to the Reuss isostress model.

The modulus of the bulk aluminum alloy remained relatively constant at about $70 \mathrm{GPa}$ at temperatures from 25 to $300{ }^{\circ} \mathrm{C}$, decreased between 300 and $400{ }^{\circ} \mathrm{C}$ to $30 \mathrm{GPa}$, and was too compliant to reliably test at $500{ }^{\circ} \mathrm{C}$. The elastic moduli of the LO-MCCs remained relatively constant at about $200 \mathrm{GPa}$ up to $300{ }^{\circ} \mathrm{C}$ and decreased linearly above this temperature to about $130 \mathrm{GPa}$ at $500{ }^{\circ} \mathrm{C}$. The Halpin-Tsai predictions overestimated the stiffness of the BE-MCCs and SA-MCCs in the LO orientation. The moduli in the transverse orientations were lower than those of the LO specimens and decreased linearly from a maximum stiffness of $\sim 130 \mathrm{GPa}$ at $25^{\circ} \mathrm{C}$ to a minimum of $\sim 85 \mathrm{GPa}$ at $500{ }^{\circ} \mathrm{C}$. Agreement between the Halpin-Tsai calculations and the transverse data was, in general, better than that in the LO orientation.

\section{Flexural strength}

Representative load-displacement curves are shown in Fig. 6. The composites presented linear-elastic behavior until fracture in the LO direction regardless of test temperature and despite evidence of extensive plastic deformation of the metal at high temperature. The roomtemperature load-displacement curves in the transverse directions were also linear-elastic until fracture in all cases, but the BE-MCCs tested in the TR2 orientation showed serrations in the curves. The serrations are indicative of intermittent crack propagation due to differences in the microstructure along the crack path. The specimens tested in the transverse orientations at high temperature showed nonlinear load-displacement curves, and the degree of nonlinearity increased with temperature.

The average value of $\sigma_{\mathrm{f}}$ of the MCCs and the Al alloy are shown as a function of temperature for each orientation in Fig. 7. The strength of the bulk Al-Si-Mg decreased slightly between 25 and $200^{\circ} \mathrm{C}$, from 215 to $170 \mathrm{MPa}$, and was drastically weaker at higher temperatures. As was the case with the elastic modulus, the strength of the MCCs was anisotropic, and the specimens tested in the LO direction were consistently stronger than those tested in the TR1 and TR2 orientations over the entire temperature range. Moreover, the evolution of $\sigma_{f}$ with temperature was different in the LO and transverse orientations.

The LO strength decreased linearly from about 


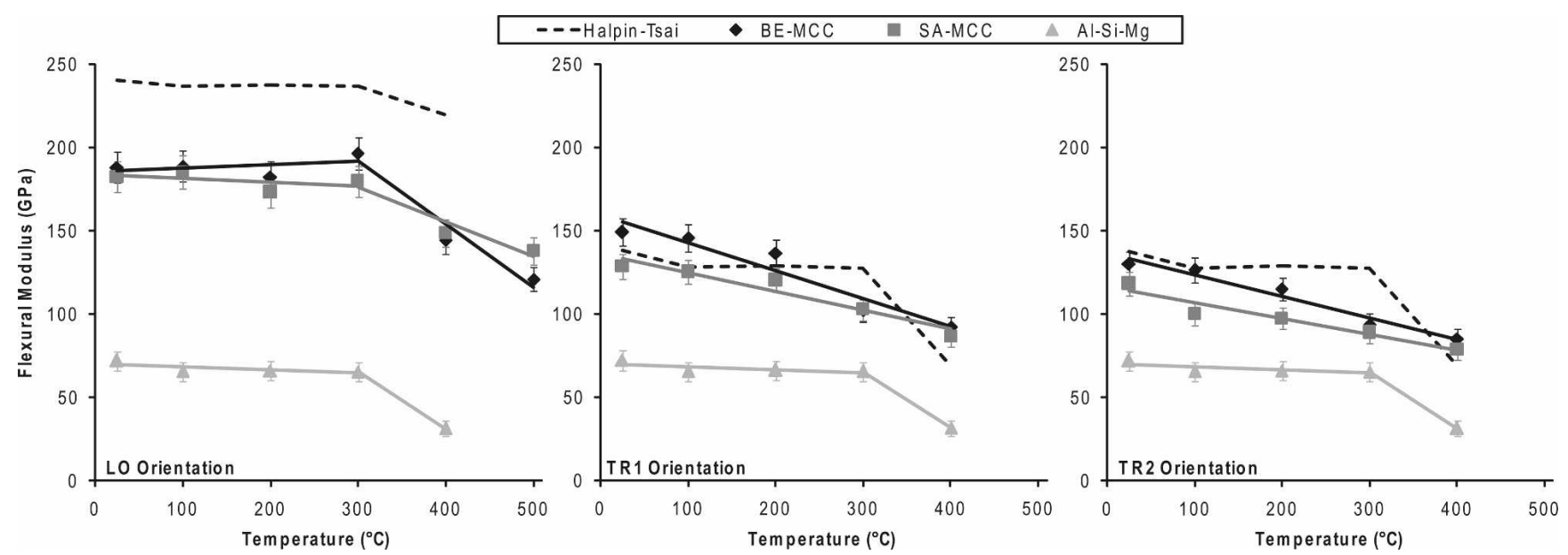

FIG. 5. Flexural modulus versus temperature for the LO, TR1, and TR2 orientations of the BE-MCC and SA-MCC, and the bulk Al-Si-Mg alloy. The dashed lines represent Halpin-Tsai predictions for the modulus of a uniaxial composite. ${ }^{21}$ The error bars represent one standard deviation.

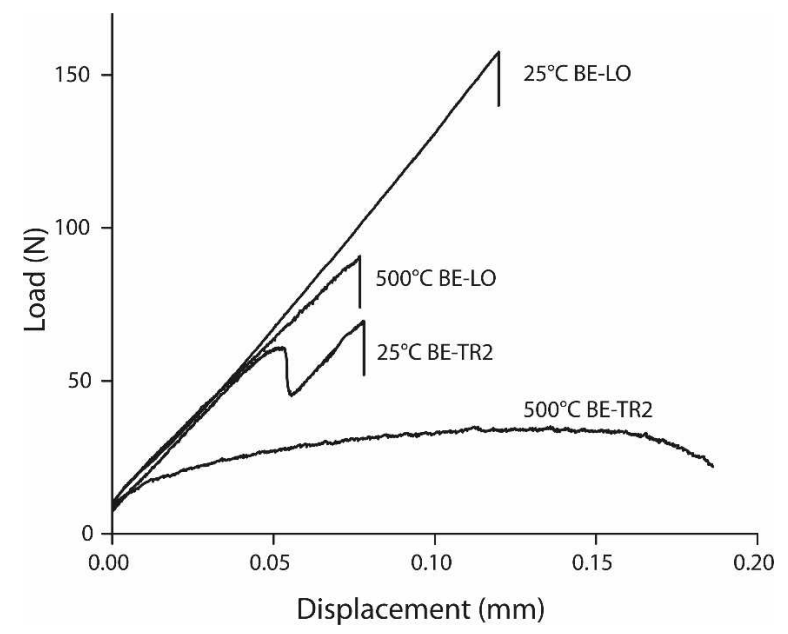

FIG. 6. Load-displacement curves of BE-MCCs tested in the LO and TR2 orientation at $25^{\circ} \mathrm{C}$ and $500{ }^{\circ} \mathrm{C}$.

$300 \mathrm{MPa}$ at $25^{\circ} \mathrm{C}$ to $150 \mathrm{MPa}$ at $500{ }^{\circ} \mathrm{C}$ and was always greater than that of the metal. In contrast, the transverse strengths were constant within the experimental scatter from ambient temperature up to $200{ }^{\circ} \mathrm{C}$, and these composites were weaker than the bulk $\mathrm{Al}-\mathrm{Si}-\mathrm{Mg}$ alloy. The transverse strengths decreased linearly from 200 to $500{ }^{\circ} \mathrm{C}$, but the composites were stronger than the bulk alloy above $200{ }^{\circ} \mathrm{C}$.

\section{Fracture toughness}

The average values of the toughness of the Al alloy and of the MCCs in the LO and transverse orientations are plotted in Fig. 8 as a function of temperature. The toughness of the bulk alloy, compared with that of some $\mathrm{Al}$ alloys,${ }^{32}$ was low due to the large volume fraction and the size of the primary Si crystals and $\mathrm{Mg}_{2} \mathrm{Si}$ precipitates. Moreover, $\mathrm{K}_{\mathrm{IC}}$ decreased rapidly above $200^{\circ} \mathrm{C}$, following a trend similar to that found for $\sigma_{\mathrm{f}}$. $\mathrm{K}_{\mathrm{IC}}$ of the MCCs also followed the trends of $\sigma_{\mathrm{f}}$. The $\mathrm{LO} \mathrm{K}_{\mathrm{IC}}$ was greater than the TR1 or TR2 $\mathrm{K}_{\mathrm{IC}}$, particularly at ambient temperature, and decreased linearly with temperature. The $\mathrm{K}_{\mathrm{IC}}$ in the TR1 and TR2 orientations was relatively constant from 25 to $200{ }^{\circ} \mathrm{C}$ and decreased linearly above this temperature.

\section{DISCUSSION}

\section{A. Elastic behavior}

The room-temperature elastic moduli of BE-MCCs have been previously measured, using pulse-echo ultrasonic-velocity measurements, and were reported as 158 and 91-119 GPa, respectively, for the LO and transverse samples. ${ }^{8}$ The results for the modulus in bending (Fig. 5) were higher at ambient temperature, but these composites contained less residual porosity and carbon when compared to the samples tested using pulse-echo. The elastic moduli of the MCCs in the LO direction also compared well to results published for $\mathrm{SiC}$ particle $\left(\mathrm{SiC}_{\mathrm{p}}\right)$ reinforced $\mathrm{Al}-\mathrm{Si}-\mathrm{Mg} \mathrm{MCCs}$ prepared by pressureless infiltration. Moduli from 165 to $226 \mathrm{GPa}$ were reported for samples with $41-54$ vol\% $\mathrm{SiC}$ and $3-8$ vol\% porosity. ${ }^{33}$

To gauge the $\mathrm{Al}$ alloy contribution to the composite stiffness, a comparison with the porous wood-derived $\mathrm{SiC}$ is needed. The elastic moduli of $\mathrm{BE}-\mathrm{SiC}$ and $\mathrm{SA}-$ $\mathrm{SiC}$, measured in compression with the applied load in the axial direction, were 116 and $23 \mathrm{GPa}$, respectively, while the moduli with the load perpendicular to the pore channels were 16 and $7 \mathrm{GPa} .{ }^{12}$ These data indicated that the microstructure (i.e., spatial distribution of pores for a given volume fraction of porosity) strongly influenced the $\mathrm{SiC}$ mechanical properties, but this was not the case for the MCCs.

The moduli for the BE-MCCs and SA-MCCs were equal within experimental error, which suggests that eliminating the porosity via aluminum infiltration decreases the influence of the wood characteristics. This 

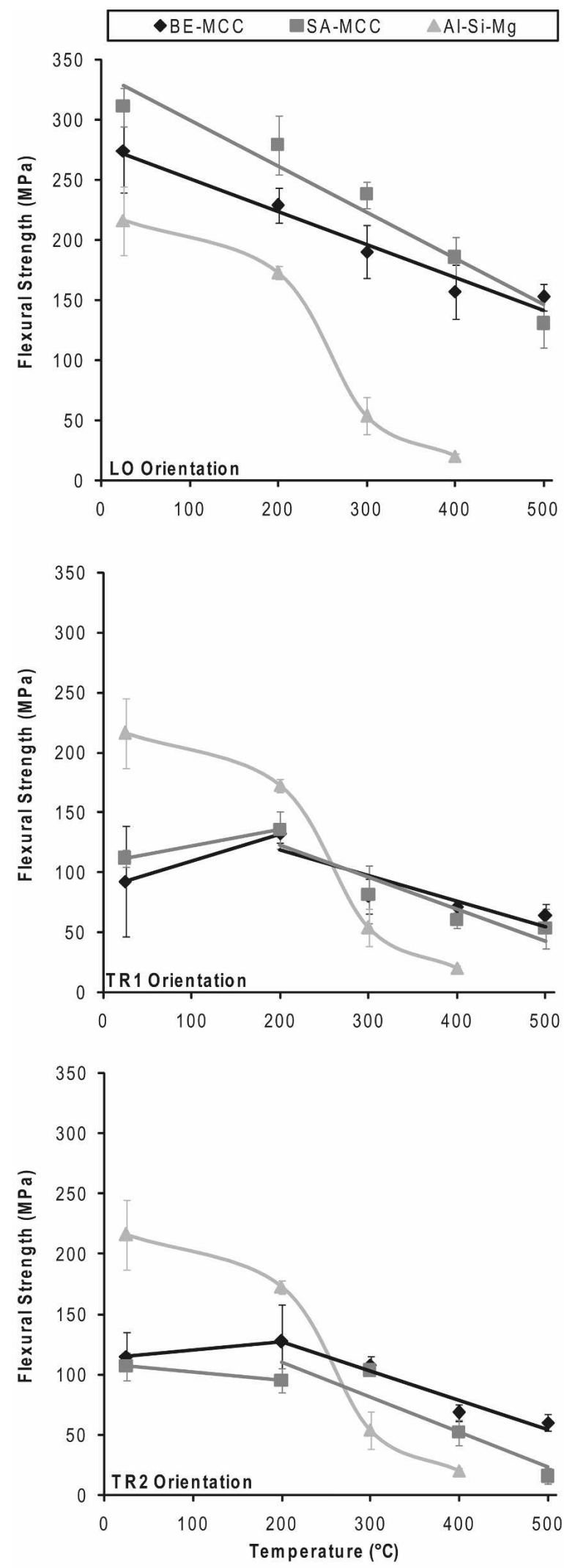

FIG. 7. Flexural strength versus temperature for the LO, TR1, and TR2 orientations of the BE-MCC, the SA-MCC, and the bulk Al-Si$\mathrm{Mg}$ alloy. The error bars represent one standard deviation. leads to a stronger dependence on the volume fractions of the ceramic and metal phases and on the test orientation. The SA-SiC benefits more from the $\mathrm{Al}$ infiltration, where LO and TR moduli were improved by factors of 11 and 18 , respectively, compared to improvements of less than twofold and sixfold for the BE-SiC. The larger increases in TR moduli (18 and 6 times greater, respectively) versus the LO moduli (11 and $<2$ times greater, respectively) correspond to a reduction in the anisotropy in the moduli of the composites.

The stiffness of porous materials, such as woodderived $\mathrm{SiC}$, is dependent on microstructural features including the connectivity and thickness of the pore walls, the presence of defects, and orientation. ${ }^{34}$ Variations in these features can change the dominant deformation mode from stretching to bending and will alter the stiffness of the material. In contrast, the stiffness of the MCCs is controlled by load transfer between phases, which depends on the spatial distribution of phases. ${ }^{35} \mathrm{In}$ the case of the BE-MCCs and SA-MCCs, the microstructure consists of a three-dimensionally continuous $\mathrm{SiC}$ phase and long $\mathrm{Al}$ alloy fibers oriented in the $\mathrm{LO}$ direction. The elastic behavior of this microstructure should follow an isostrain model in the LO direction and an isostress model in the transverse orientations. While agreement between the Halpin-Tsai model and the transverse data is relatively good, the LO data fall well below the predicted stiffnesses. This is due to the pore morphology of the wood-derived $\mathrm{SiC}$ and the structure of the resulting MCCs. ${ }^{31}$ While the Halpin-Tsai calculations are based on an ideal structure, the MCCs contain a nonideal microstructure with nonlinear and nonparallel Alfilled pores.

In addition to the decreased stiffness associated with the nonideal wood precursor microstructure, another possible source of experimental scatter is interface decohesion. Instances of decohesion, which were observed in both the BE-MCCs and SA-MCCs, were more apparent in the SA-MCCs [indicated by the arrow in Fig. 2(j)]. Interface decohesion can be triggered by the residual stresses that develop upon cooling after melt infiltration due to the thermal-expansion mismatch between the $\mathrm{SiC}$ and the $\mathrm{Al}$ alloy.

\section{B. Bending strength and fracture mechanisms}

At room temperature, the load-displacement curves corresponding to the bending and fracture tests of the $\mathrm{Al}$ alloy were linear elastic until fracture. This brittle behavior is a result of the presence of the large primary $\mathrm{Si}$ crystals. In fact, the strain-to-failure in tension of the $\mathrm{Al}-\mathrm{Si}-\mathrm{Mg}$ alloy at $25^{\circ} \mathrm{C}$ was only $0.7 \%$, and the ductility increased with temperature up to $8.5 \%$ at $400{ }^{\circ} \mathrm{C}$. Composite specimens tested in the LO orientation also presented linear-elastic behavior at ambient temperature, and the nonlinearity in the load-displacement curves was 

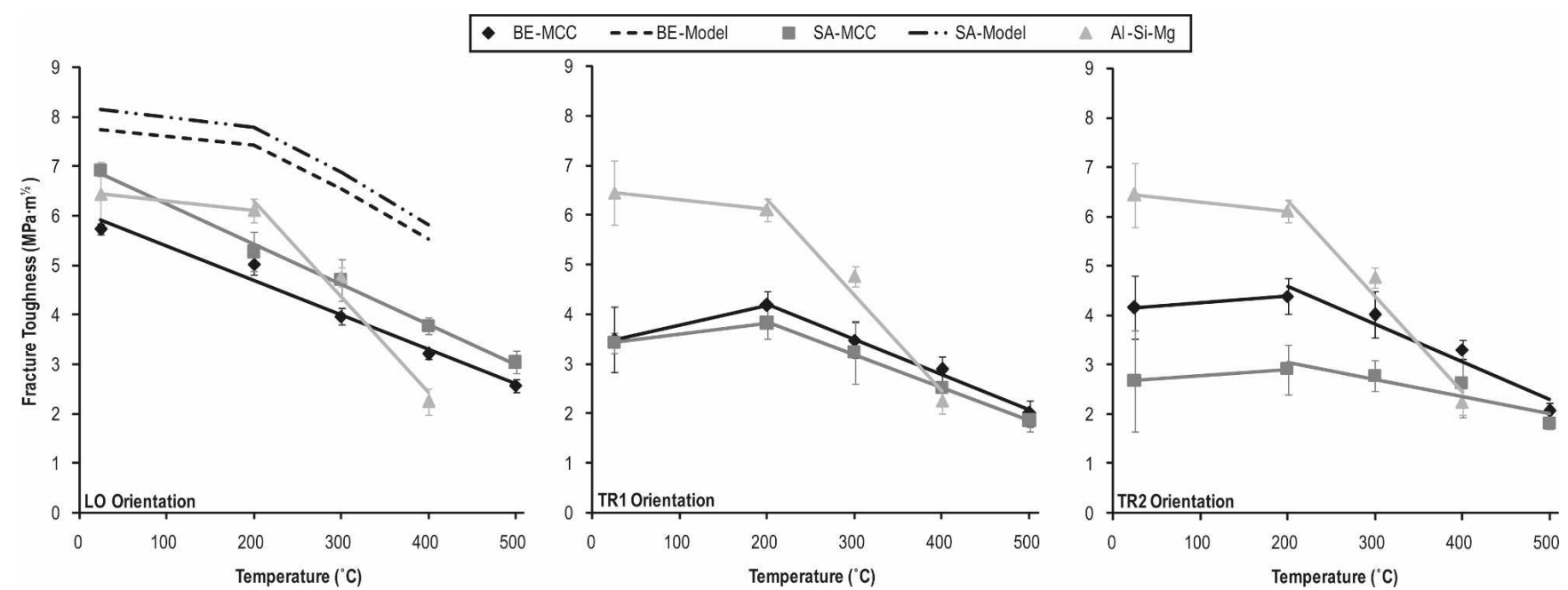

FIG. 8. Fracture tough versus temperature for the LO, TR1, and TR2 orientations of the BE-MCC, the SA-MCC, and the bulk Al-Si-Mg alloy. The error bars represent one standard deviation. Also plotted, for the LO orientation, are $\mathrm{K}_{\mathrm{IC}}$ models calculated following the model of Ashby et al. ${ }^{19}$

limited even at $500{ }^{\circ} \mathrm{C}$ (Fig. 6). This behavior reflects the presence of a continuous $\mathrm{SiC}$ phase, which limits macroscopic plastic deformation; however, differences in the microscopic fracture mechanisms between the ambient and the elevated temperature were observed. While the $\mathrm{Al}$ fibers in the fracture surfaces showed little evidence of plastic deformation at $25^{\circ} \mathrm{C}$ [Fig. 9(a)], the infiltrated Al tended to span the crack opening and then fail by ductile mechanisms of void nucleation and growth at high temperatures [Fig. 9(b)]. Figure 9(c) presents a lateral view in which a bridging metal inclusion has completely failed during a test at $500{ }^{\circ} \mathrm{C}$. The data from the current study agree with data for $\mathrm{SiC}_{\mathrm{p}}$-reinforced $\mathrm{Al}-\mathrm{Si}$ -
Mg MCCs with 41-54 vol\% SiC and 3-8 vol\% residual porosity, which were between 183 and $298 \mathrm{MPa}$, respectively. ${ }^{33}$

The composite specimens tested in the transverse orientations presented brittle behavior at ambient temperature, which corresponds with the straight crack paths observed and with the brittle appearance of the fracture surfaces, as shown in Fig. 10(a) of a BE-MCC tested in the TR1 orientation. The extensive contribution of the plastic deformation of the $\mathrm{Al}$ alloy to the nonlinear behavior in the load-displacement curves was observed at high temperature [Figs. 10(b) and 10(c)]. The bending strength in the TR1 and TR2 orientations of the
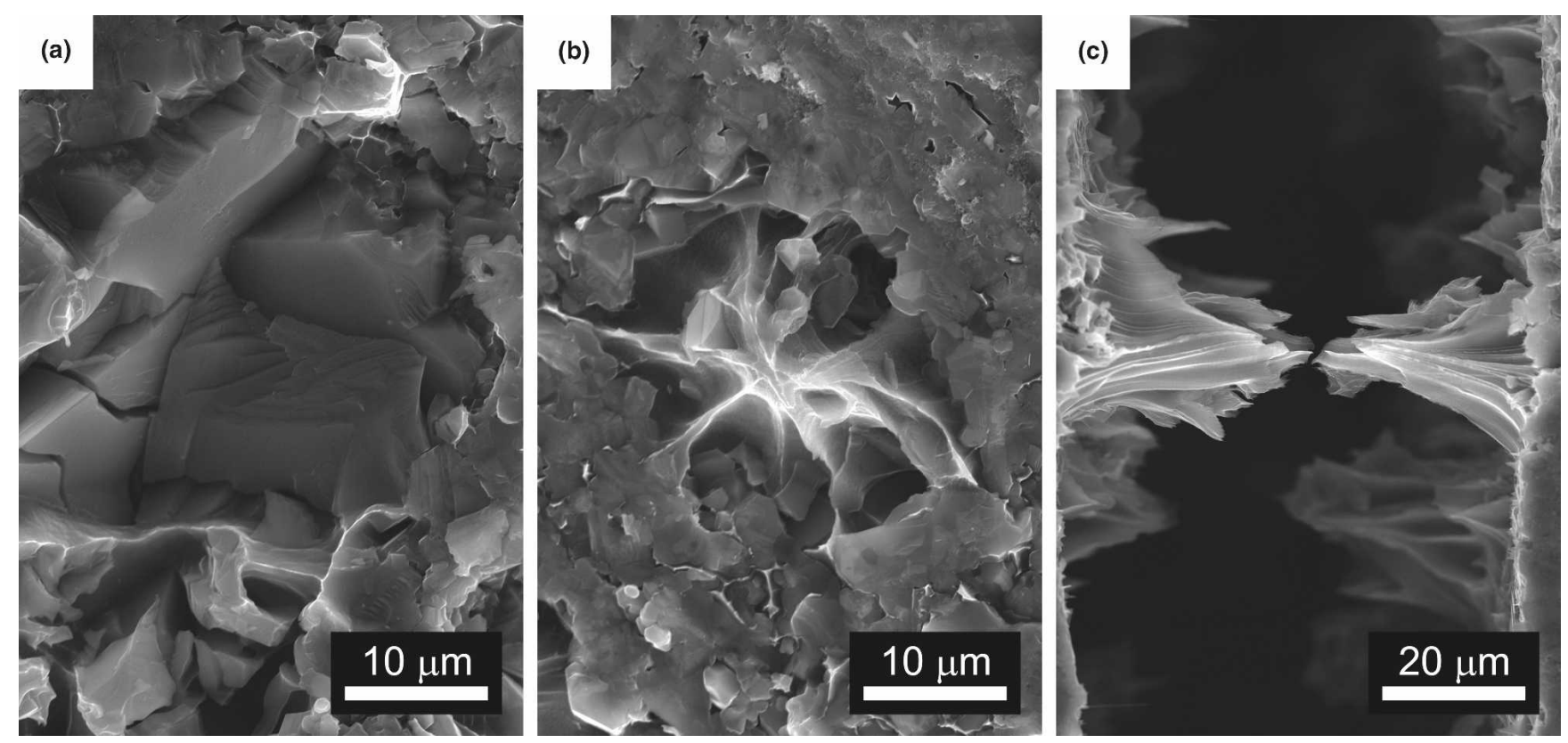

FIG. 9. SEM micrographs of fractured BE-MCC specimens in the LO orientation: (a) $25{ }^{\circ} \mathrm{C}$ fracture surface showing the brittle fracture of the metal within a pore; (b) $500{ }^{\circ} \mathrm{C}$ fracture surface showing the ductile pullout at high temperature of the metal within a pore; and (c) $500{ }^{\circ} \mathrm{C}$ crack profile showing a failed bridging ligament. 

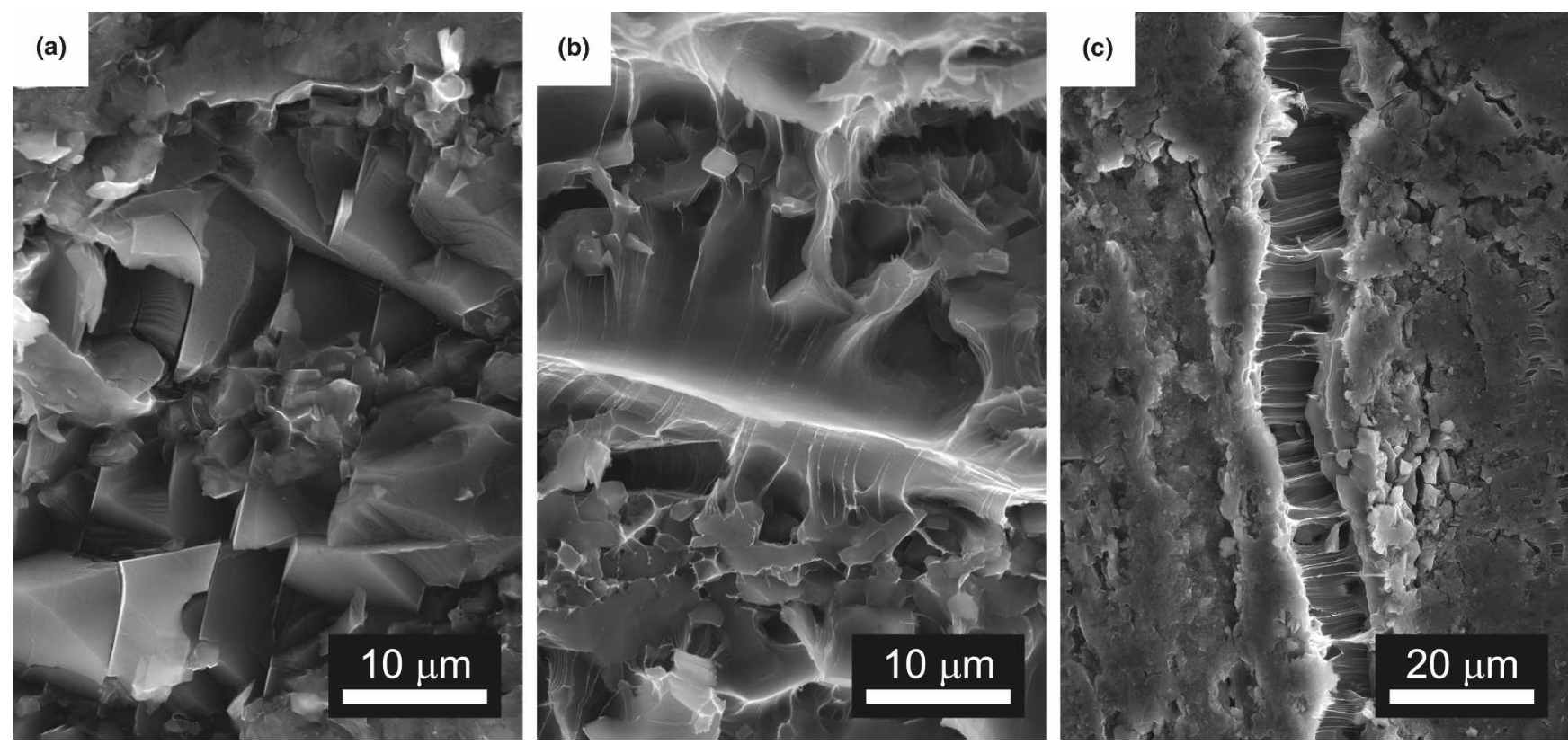

FIG. 10. SEM micrographs of fractured BE-MCC specimens in the TR1 orientation: (a) $25^{\circ} \mathrm{C}$ fracture surface showing the brittle fracture due to the large $\mathrm{Si}$ crystals and $\mathrm{Mg}_{2} \mathrm{Si}$ precipitates; (b) $500{ }^{\circ} \mathrm{C}$ fracture surface showing the ductile behavior of the metal at high temperature; and (c) $500{ }^{\circ} \mathrm{C}$ crack profile showing the $\mathrm{Al}-\mathrm{Si}-\mathrm{Mg}$ alloy spanning the crack width.

BE-based composites at $25^{\circ} \mathrm{C}$ were equivalent to those measured in specimens infiltrated with pure aluminum, which had strengths of 81 and 92-95 $\mathrm{MPa}$, respectively, for the TR1 and TR2 orientations. ${ }^{7}$ The loaddisplacement curves of the pure Al-MCCs also exhibited serrations, which were attributed to the varying density resulting from the growth rings. This is supported by the results from the current work: the serrations were observed in the BE-TR2 MCCs but not the SA-TR2 specimens, which lacked the repetitive density changes due to growth rings.

\section{Fracture toughness}

The room-temperature $\mathrm{K}_{\mathrm{IC}}$ of porous wood-derived $\mathrm{SiC}$ was reported as $1.25 \mathrm{MPa} \cdot \mathrm{m}^{1 / 2}$ in the $\mathrm{LO}$ orientation and 0.59 and $0.24 \mathrm{MPa} \cdot \mathrm{m}^{1 / 2}$ in transverse orientations, respectively, for porous $\mathrm{BE}-\mathrm{SiC}$ and $\mathrm{SA}-\mathrm{SiC}^{12} ; \mathrm{K}_{\mathrm{IC}}$ of bulk $\mathrm{SiC}$ is $2.4 \mathrm{MPa} \cdot \mathrm{m}^{1 / 2}{ }^{36}$ Although $\mathrm{K}_{\mathrm{IC}}$ of the $\mathrm{Al}$ alloy was poor due to the presence of the large Si crystals and $\mathrm{Mg}_{2} \mathrm{Si}$ precipitates, $\mathrm{K}_{\mathrm{IC}}$ of the porous $\mathrm{SiC}$ increased significantly with the Al infiltration. The improvements in the $\mathrm{LO}$ direction were due to the bridging effect of the $\mathrm{Al}$ fibers [Fig. 9(c)], while the increased $\mathrm{K}_{\mathrm{IC}}$ values in the transverse directions were moderate.

Based on experimental evidence, the increase in $\mathrm{K}_{\mathrm{IC}}$ in the $\mathrm{LO}$ orientation was due to the bridging effect of the infiltrated $\mathrm{Al}$ within the pores. The metal in the pores acted as constrained fibers that were stretched as the crack opened and absorbed energy, which contributed to $\mathrm{K}_{\mathrm{IC}}$. The increase in $\mathrm{K}_{\mathrm{IC}}$ due to this mechanism was modeled by Ashby et al. ${ }^{19}$ as

$$
\Delta K_{\mathrm{IC}}=E\left[C V_{f} \frac{\sigma_{y}}{E} a_{0}\right]^{1 / 2},
$$

where $E$ is the elastic modulus of the metal, $V_{f}$ is the volume fraction of metal intersected by a crack, $\sigma_{y}$ is the yield stress of the metal, $a_{0}$ is the radius of the metal inclusion, and $C$ stands for a constant that depends on the constraint of the metal within the ceramic and is approximated as

$$
C=2.5 \frac{u_{\mathrm{max}}}{a_{0}},
$$

where $u_{\max }$ is the crack opening displacement at failure of a bridging ligament. ${ }^{19}$ This constant depends on only the interface strength and is independent of the diameter of the inclusion. For this study, $E$ and $\sigma_{y}$ were measured using tensile tests of the bulk $\mathrm{Al}$ alloy. $C$ was calculated by using the SEM and analysis software (Quartz PCI; Quartz Imaging Corp., Vancouver, BC, Canada). The diameter and extent of the protrusion of failed $\mathrm{Al}$ bridges were measured from images of crack profiles and fracture surfaces of specimens fractured at each temperature.

Equation (3) considers a composite with inclusions of uniform size $\left(a_{0}\right)$ representing a certain volume fraction $\left(V_{f}\right)$, but the BE-MCCs and SA-MCCs present a nonideal situation with varying numbers of irregularly shaped inclusions of different sizes. To account for this, a midpoint Riemann sum was calculated using the incremental function of the pore volume fraction versus pore diameter data for the BE-SiC and SA-SiC, and this was added to 
the $\mathrm{K}_{\mathrm{IC}}$ of the porous $\mathrm{SiC}\left(1.25\right.$ and $1.36 \mathrm{MPa} \cdot \mathrm{m}^{1 / 2}$, respectively, for the $\mathrm{BE}-\mathrm{SiC}$ and $\mathrm{SA}-\mathrm{SiC}^{12}$ ) to calculate the total $\mathrm{K}_{\mathrm{IC}}$ of the composites,

$$
K_{\mathrm{IC}}=E\left[C \frac{\sigma_{y}}{E}\right]^{1 / 2} \cdot \Sigma\left[V_{f} a_{0}\right]^{1 / 2}+K_{\mathrm{IC}, \mathrm{SiC}}
$$

where $\mathrm{K}_{\mathrm{IC}, \mathrm{SiC}}$ is the toughness of the porous $\mathrm{SiC}$.

The predictions of the modified model by Ashby et al. ${ }^{19}$ are plotted in Fig. 8 together with the experimental results, and they are in relatively good agreement. It is important to note that the model predicts a higher $\mathrm{K}_{\mathrm{IC}}$ for the SA-MCCs due to the larger pore radius, and this is confirmed by the experimental results at all temperatures but $200{ }^{\circ} \mathrm{C}$.

\section{CONCLUSIONS}

Melt infiltration of an aluminum alloy into porous wood-derived $\mathrm{SiC}$ is an effective means to manufacture MCCs. The resulting material consists of interconnected $\mathrm{SiC}$ with $\mathrm{Al}$ fibers oriented in the axial and radial directions of the precursor wood. The modulus, strength, and touchness in the LO direction were similar to those reported in MCCs with equivalent volume fractions of both phases. The corresponding properties in the transverse direction were lower, and this behavior reproduced the differences observed in the properties of the porous $\mathrm{SiC}$. Overall, the room-temperature strength and $\mathrm{K}_{\mathrm{IC}}$ were maintained up to $200{ }^{\circ} \mathrm{C}$, and then decreased due to the marked reduction of the flow stress of the $\mathrm{Al}$ alloy above this temperature. The microstructure of the precursor wood had little influence on the stiffness and strength of the MCCs, as opposed to the behavior found in the porous $\mathrm{SiC}$.

The analysis of the experimental results showed that the deformation of the composites in the LO direction was controlled by the rigid $\mathrm{SiC}$ skeleton, leading to brittle behavior throughout the entire temperature range. Although the load transfer from the $\mathrm{Al}$ to the $\mathrm{SiC}$ was efficient, the LO composite stiffness was below that predicted by Halpin-Tsai due to the nonideal microstructure. Moreover, the increase in $\mathrm{K}_{\mathrm{IC}}$ due to the $\mathrm{Al}$ followed the predictions of the model by Ashby et al. ${ }^{19}$ for toughening ceramics by incorporating ductile inclusions. MCCs made from wood with pores having a larger diameter are tougher than those with the same volume fraction of smaller diameter metal inclusions.

In the transverse orientation, the $\mathrm{Al}$ alloy played a more important role, as is demonstrated by the extent of the nonlinear deformation of the BE-TR2 MCC at $500{ }^{\circ} \mathrm{C}$. The stiffness of the TR1 and TR2 MCCs were closer to the Halpin-Tsai model for the transverse stiffness of a uniaxial composite, indicating that the load transfer from the $\mathrm{Al}$ to the $\mathrm{SiC}$ in the transverse direction was less efficient, leading to a lower modulus, strength, and $\mathrm{K}_{\mathrm{IC}}$.

\section{ACKNOWLEDGMENTS}

The financial support from the National Science Foundation through grants DMR-0244258/0710630, from the Ministerio de Educación y Ciencia through grant MAT2007-29278-E, and from the Comunidad de Madrid through the Materiales Estructurales Avanzados ESTRUMAT program (S-0505/MAT-0077) is gratefully acknowledged.

\section{REFERENCES}

1. A.R. de Arellano-López, J. Martinez-Fernandez, P. Gonzalez, C. Dominguez, V. Fernandez-Quero, and M. Singh: Biomorphic SiC: A new engineering ceramic material. Int. J. Appl. Ceram. Technol. 1, 56 (2004).

2. J. Martinez-Fernandez, F.M. Valera-Feria, and M. Singh: High temperature compressive mechanical behavior of biomorphic silicon carbide ceramics. Scripta Mater. 43, 813 (2000).

3. M. Presas, J.Y. Pastor, J. Llorca, A.R. de Arellano-López, J. Martinez-Fernandez, and R.E. Sepulveda: Mechanical behavior of biomorphic Si/SiC porous composites. Scripta Mater. 53, 1175 (2005).

4. M. Singh and J.A. Salem: Mechanical properties and microstructure of biomorphic silicon carbide ceramics fabricated from wood precursors. J. Eur. Ceram. Soc. 22, 2709 (2002).

5. M. Singh and B.M. Yee: Reactive processing of environmentally conscious, biomorphic ceramics from natural wood precursors. J. Eur. Ceram. Soc. 24, 209 (2004).

6. F.M. Varela-Feria, J. Martinez-Fernandez, A.R. de Arellano-Lopez, and M. Singh: Low density biomorphic silicon carbide: Microstructure and mechanical properties. J. Eur. Ceram. Soc. 22, 2719 (2002).

7. A. Herzog, U.F. Vogt, S. Siegmann, and O. Beffort: Aluminium metal matrix composites based on biomorphic silicon carbide. Adv. Eng. Mater. 8, 980 (2006).

8. T.E. Wilkes, M.L. Young, R.E. Sepulveda, D.C. Dunand, and K.T. Faber: Composites by aluminum infiltration of porous silicon carbide derived from wood precursors. Scripta Mater. 55, 1083 (2006).

9. C. Zollfrank, N. Travitzky, H. Sieber, T. Selchert, and P. Greil: Biomorphous SiSiC/Al-Si ceramic composites manufactured by squeeze casting: Microstructure and mechanical properties. $A d v$. Eng. Mater. 7, 743 (2005).

10. J.M. Dinwoodie: Wood: Nature's Cellular, Polymeric, FibreComposite (Institute of Metals, London, Brookfield, VT, 1989).

11. L.J. Gibson and M.F. Ashby: Cellular Solids: Structure and Properties, 2nd ed. (Cambridge University Press, Cambridge, UK, New York, 1997).

12. V.S. Kaul, K.T. Faber, R. Sepulveda, A.R. de Arellano-López, and J. Martinez-Fernandez: Precursor selection and its role in the mechanical properties of porous $\mathrm{SiC}$ derived from wood. Mater. Sci. Eng., A 428, 225 (2006).

13. K.E. Pappacena, K.T. Faber, H. Wang, and W.D. Porter: Thermal conductivity of porous silicon carbide derived from wood precursors. J. Am. Ceram. Soc. 90, 2855 (2007)

14. A. Mortensen, V.J. Michaud, and M.C. Flemings: Pressureinfiltration processing of reinforced aluminum. JOM J. Miner Met. Mater. Soc. 45, 36 (1993).

15. A.C. Ferro and B. Derby: Wetting behavior in the Al-Si/SiC system: Interface reactions and solubility effects. Acta Metall. Mater. 43, 3061 (1995)

16. M.I. Pech-Canul, R.N. Katz, and M.M. Makhlouf: Optimum parameters for wetting silicon carbide by aluminum alloys. Metall. Mater. Trans. A 31, 565 (2000). 
17. B.D. Flinn, C.S. Lo, F.W. Zok, and A.G. Evans: Fractureresistance characteristics of a metal-toughened ceramic. $\underline{J . A m}$. Ceram. Soc. 76, 369 (1993).

18. L.S. Sigl, P.A. Mataga, B.J. Dalgleish, R.M. McMeeking, and A.G. Evans: On the toughness of brittle materials reinforced with a ductile phase. Acta Metall. 36, 945 (1988).

19. M.F. Ashby, F.J. Blunt, and M. Bannister: Flow characteristics of highly constrained metal wires. Acta Metall. 37, 1847 (1989).

20. H.E. Dève and S. Schmauder: Role of interface properties on the toughness of brittle matrix composites reinforced with ductile fibers. J. Mater. Res. 7, 3132 (1992).

21. K.K. Chawla: Composite Materials: Science and Engineering, 2nd ed. (Springer, New York, 1998).

22. J.T. Blucher: Discussion of a liquid-metal pressure infiltration process to produce metal matrix composites. J.Mater. Process. Technol. 30, 381 (1992).

23. ASTM C373-88: Standard Test Method for Water Absorption, Bulk Density, Apparent Porosity, and Apparent Specific Gravity of Fired Whiteware Products (ASTM International, West Conshohocken, PA, 1988).

24. ASTM E8: Standard Test Methods for Tension Testing of Metallic Materials (ASTM International, West Conshohocken, PA, 2001).

25. ASTM C1161-02c: Standard Test Method for Flexural Strength of Advanced Ceramics at Ambient Temperature (ASTM International, West Conshohocken, PA, 2003).

26. G.V. Guinea, J.Y. Pastor, J. Planas, and M. Elices: Stress intensity factor, compliance and CMOD for a general three-point-bend beam. Int. J. Fract. 89, 103 (ASTM International, West Conshohocken, PA, 1998).
27. ASTM C1421-01b: Standard Test Method for Determination of Fracture Toughness of Advanced Ceramics at Ambient Temperature (ASTM International, West Conshohocken, PA, 2002).

28. Y.X. Wang, S.H. Tan, and D.L. Jiang: The effect of porous carbon preform and the infiltration process on the properties of reactionformed SiC. Carbon 42, 1833 (2004).

29. Q.G. Wang and C.J. Davidson: Solidification and precipitation behaviour of Al-Si-Mg casting alloys. J.Mater. Sci. 36, 739 (2001).

30. A. Mortensen and I. Jin: Solidification processing of metal matrix composites. Int. Mater. Rev. 37, 101 (1992).

31. V.S. Kaul and K.T. Faber: Nanoindentation analysis of the elastic properties of porous SiC derived from wood. Scripta Mater. $\mathbf{5 8}$. $886(2008)$.

32. G.T. Hahn and A.R. Rosenfield: Metallurgical factors affecting fracture toughness of aluminum-alloys. Metall. Trans. A 6, 653 (1975).

33. M.I. Pech-Canul and M.M. Makhlouf: Processing of Al-SiCp metal matrix composites by pressureless infiltration of SiCp preforms. J. Mater. Svnth. Proc. 8, 35 (2000).

34. A.R. Studart, U.T. Gonzenbach, E. Tervoort, and L.J. Gauckler: Processing routes to macroporous ceramics: A review. ram. Soc. 89, 1771 (2006).

35. T.W. Clyne and P.J. Withers: An Introduction to Metal Matrix Composites (Cambridge University Press, New York, 1993).

36. K.T. Faber and A.G. Evans: Intergranular crack-deflection toughening in silicon-carbide. J. Am. Ceram. Soc. 66, C94 (1983). 